\title{
STUDIES ON PATHOPHYSIOLOGICAL SIGNIFICANCE OF SYMPATHETIC ACTIVITY IN MYOCARDIAL INFARCTION
}

\author{
TAKAAKI YAO
}

$I^{\mathrm{N}}$ recent years, not a few studies have been performed on the pathophysiological role of sympathetic activity in congestive heart failure. Thanks to those studies, it is being elucidated that the sympathetic hyperactivity is contributory to improving heart failure. Studies are also under way on changes in the sympathetic activity and roles they play in the living organism in shocks of various causes. On myocardial infarction, which is a common cause of cardiogenic shock, there have been many observations showing sympathetic hyperactivity in the acute phase of myocardial infarction by means of estimating urine and plasma catecholamine (CA) ${ }^{1-4}$

Since CA, especially noradrenaline (NA), have been used in treating cardiogenic shock due to myocardial infarction, the increased level of CA in the plasma and urine may be accepted as reasonable biophylactic reactions to the onset of myocardial infarction. Corday 5 recommended pressor amines for the treatment of shock caused by myocardial infarction, for the reason that they restone the blood pressure, and consequently, increase the coronary blood flow and reduce the coronary vascular resistance. Whereas $L i l e h e i^{5}$ as well as Raab et al. ${ }^{6}$ assert that the use of CA is disadvantageous to the cardiovascular system because it increases myocardial oxygen consumption and peripheral vascular resistance.

Key Words:

Myocardial infarction

Catecholamine

Sympathetic activity

Adrenocorticosteroid
The present study intends to elucidate the role of the CA increase, namely, the sympathetic hyperactivity, in the acute stage of myocardial infarction.

\section{METHODS}

1) Clinical observation

The patients with myocardial infarction who were admitted to the Affiliated Hospital of Kobe University School of Medicine were examined for the relations of urinary excretion of CA to their clinical symptoms and laboratory findings. When patients died in the acute phase, myocardial specimens from the infarcted and intact area of the left ventricle were obtained and the CA content was assayed.

2) Experimental study on rabbits with the ligated coronary artery

A) Effects of CA on hemodynamics

Rabbits, weighing 2.0 to $3.0 \mathrm{~kg}$ were employed. They were anesthetized by intraperitoneal injection of $25 \%$ urethane, $4 \mathrm{ml} / \mathrm{kg}$. The cardiac contractility was determined by such a method that needles were directly set at two different points on the epicardium of the left ventricle, and variations in the distance between the two points were caught as variations in electric capacity. The blood pressure was determined by a catheter inserted directly into the carotid artery. Myocardial infarction was produced by ligating the anterior descending branch of the left coronary artery. Development of myocardial infarction was confirmed by the electrocardiogram. In a typical case, the S-T segments elevated in the standard lead III im-

(Received on April 17, 1974; Accepted for publication on July 21, 1975)

Department of Internal Medicine. Division I (Director; Prof. Tatsuya Tomomatsu) Kobe University

School of Medicine, Kobe 


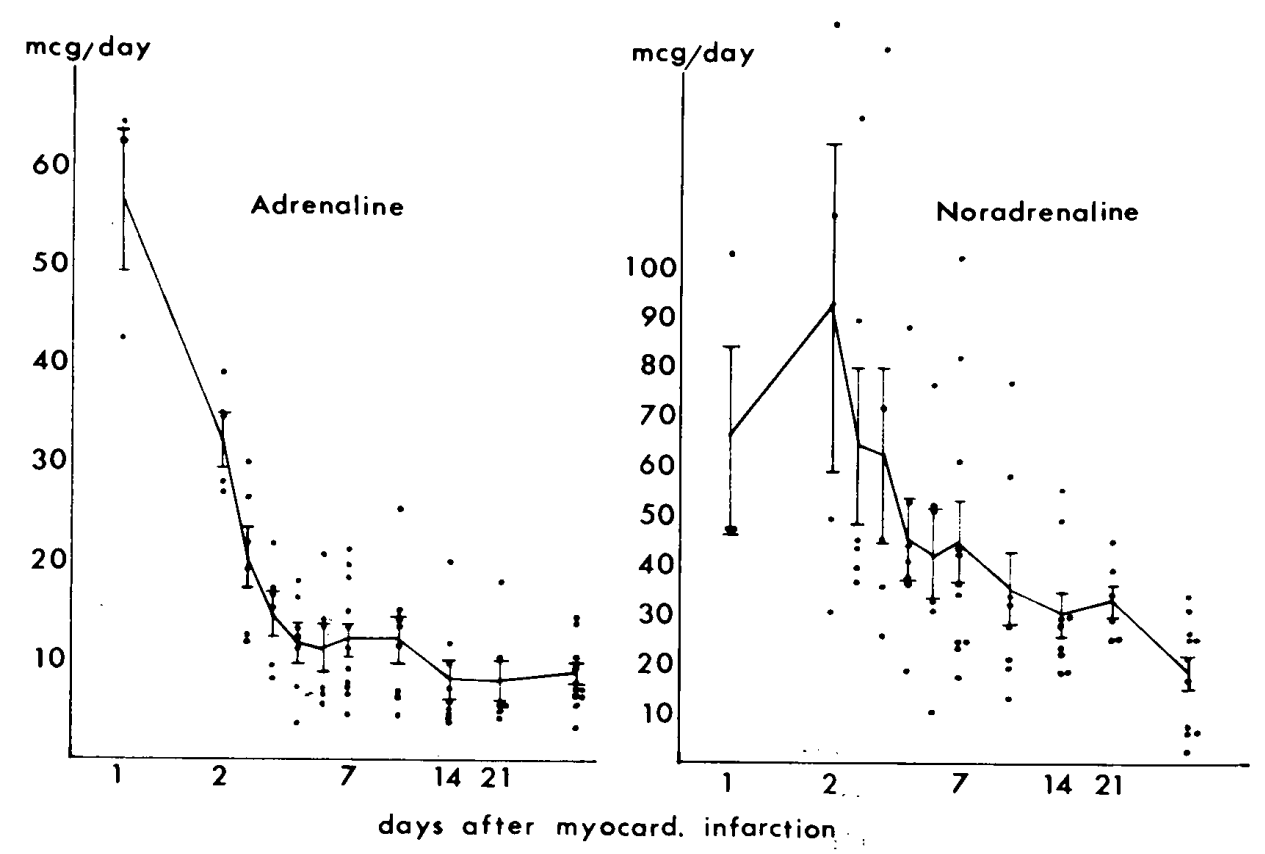

Fig.1. Changes in urinary excretion of catecholamine following myocardial infarction. Vertical lines represent the standard error of the mean.

mediately after the ligation, the $\mathrm{T}$ waves were depressed three days later.

B) Changes in the $\mathrm{CA}$ content in the myocardium, urinary excretion of $\mathrm{CA}$, and NA uptake into the myocardium

The infarcted and intact areas of the myocardium and other organs were assayed for the CA content at 6 hours, 3 days, 7 days and 14 days after the coronary ligation. Those rabbits whose coronary artery was not ligated, with the needle being only passed around the artery, were used as the control. Urine was collected every 48 hours to determine the CA excretion. Further, to examine the NA uptake capacity, $20 \mathrm{ml}$ of Ringer's solution with $100 \mathrm{mcg}$ of NA was infused into the ear vein over 30 minutes and the CA content in the infarcted and intact area. of the myocardium was determined. This was also done in the non-ligated rabbits.

Urinary CA was determined by the modified method of Euler and Flording, and also the modified method $^{8}$ of $\mathrm{Crout}^{9}$ was employed to assay the tissue $\mathrm{CA}$ content.

\section{RESULTS}

\section{1) Clinical observation}

Changes in the urinary excretion of CA following the attack of myocardial infarction are shown in Fig. 1. Both adrenaline (A) and NA excretion were very high immediately after an attack, but gradually decreased with slight fluctuation, and returned to the normal range in about one month in the majority of patients. Some of the patients with complaints of anginal attack showed increased urinary excretion of $\mathrm{CA}$ even in the chronic stage. Comparative observation of the urinary excretion of CA and other laboratory findings are described below.

Case 1 (Fig. 2) was 60 year old, male patient with anterior myocardial infarction. The urinary excretion of CA three days after the attack was markedly increased. The white blood cells and S-GOT were also increased. The leucocytes and S-GOT returned to the normal value in five days but the urinary excretion of CA remained high even seven days after the attack and returned to normal in two weeks. The blood sedimentation rate slowly increased and remained high even two weeks after.

Case 2 (Fig. 3) suffered from anterolateral infarction. His chest pain disappeared within a day. Urinary excretion of CA in this case rapidly decreased and became normal in eight days.

Case 3 (Fig. 4) suffered from extensive anterior infarction and developed shock which was treated by intravenous drip infusion of NA. Thus, urinary excretion of CA was markedly 


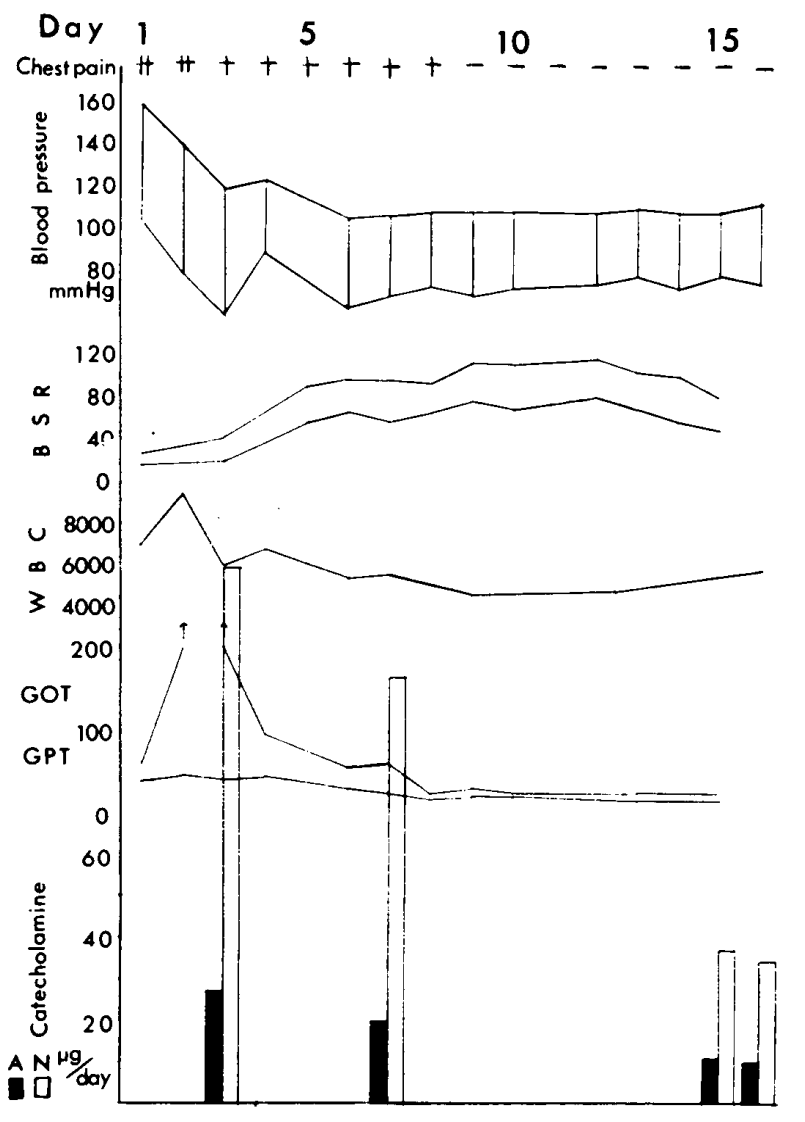

N. K. 60 y. Myocardial Infarction

Fig.2. Clinical course and changes in urinary excretion of catecholamine of Case 1 with anterior myocardial infarction.

increased, making it difficult to evaluate endogenous CA changes. However the urinary excretion of CA immediately after the attack when the patient had received no exogenous $C A$ was almost at the same level with CA in later stage when the patient received NA infusion.

Table I shows the CA contents in myocardial specimens from patients who died in the acute stage of myocardial infarction. These CA contents were determined $8,12,12$, hours after their death respectively. In all cases, the CA contents in the non-infarcted area were lower than those in the infarcted area.

2) Experimental study on rabbits with the ligated coronary artery.

A) Effects of CA on hemodynamics

Figure 5 shows decrease of contractile force and fall of the blood pressure in rabbits following coronary ligation. Fall in peripheral arterial pressure was accompanied with decrease of pulse pressure. Shown in Fig. 6 are changes in cardiac contractile force and peripheral arterial

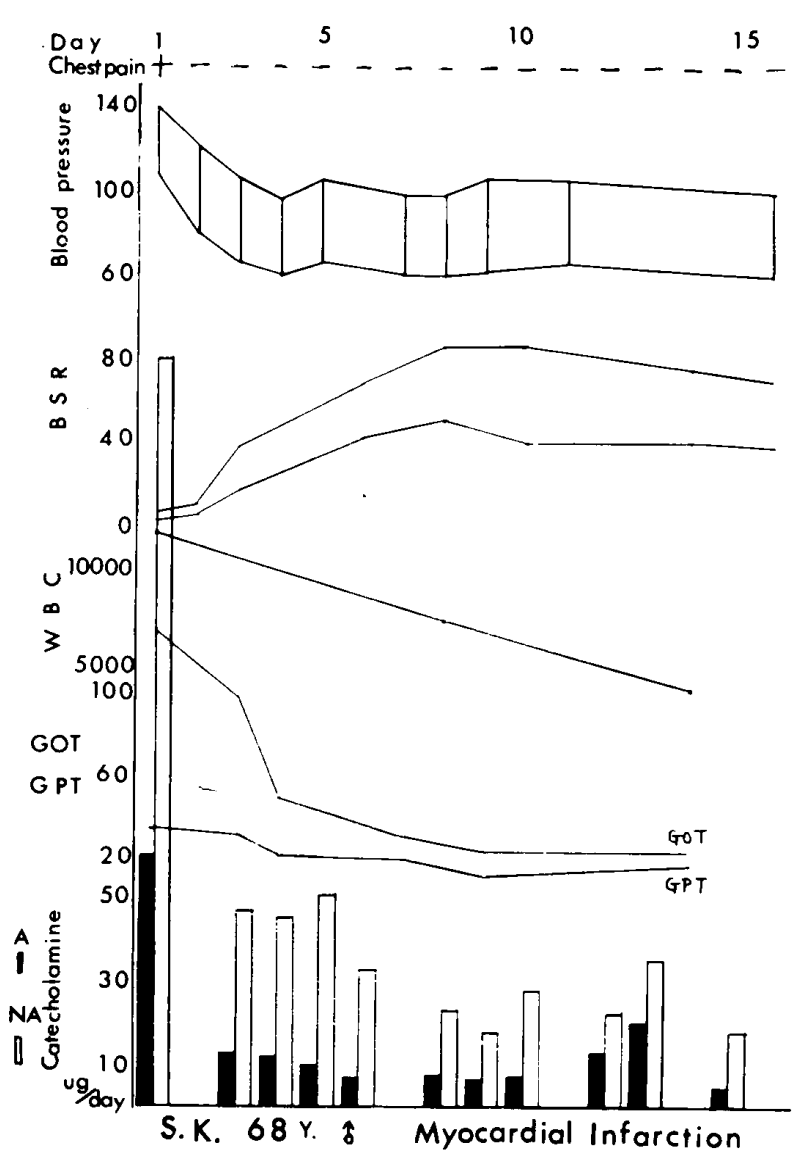

Fig.3. Clinical course and changes in urinary excretion of catecholamine of Case 2 with small anterolateral infarction.

pressure when one-shot injection of adrenaline 3 mcg per $\mathrm{kg}$ of body weight was given 30 minutes after the ligation. The control group (upper column) showed markedly increased cardiac contractility and rise in the blood pressure, whereas the group with slightly ligated coronary artery (middle column) showed less intense changes in these parameters. The group with completely ligated coronary artery (lower column) showed almost no change in cardiac contractility and slight increase of the peripheral arterial pressure. The blood pressure fell when venous return was suppressed by compressing the inferior caval vein in the stage when the blood pressure was maintained high by CA injection, and blood pressure was restored again when the compression was removed (Fig. 7). (The outline of this study was presented at the 29th Annual Meeting of Japanese Circulation Society by Tomomatsu and Ueba. ${ }^{10}$ ) B) Changes in the CA content in various organs, and effects of certain drugs on the CA content in the myocardium 
TABLE I CATECHOLAMINE CONTENT $(\mathrm{m} \mathrm{cg} / \mathrm{g})$ IN THE HEART MUSCLE IN PATIENT WITH MYOCARDIAL INFARCTION

\begin{tabular}{ccc}
\hline \hline patient & infarcted area & non-infarcted area \\
\hline H. K. male & 1.80 & 0.76 \\
H. F. female & 1.31 & 0.48 \\
T. N. male & 1.08 & 0.69 \\
\hline
\end{tabular}

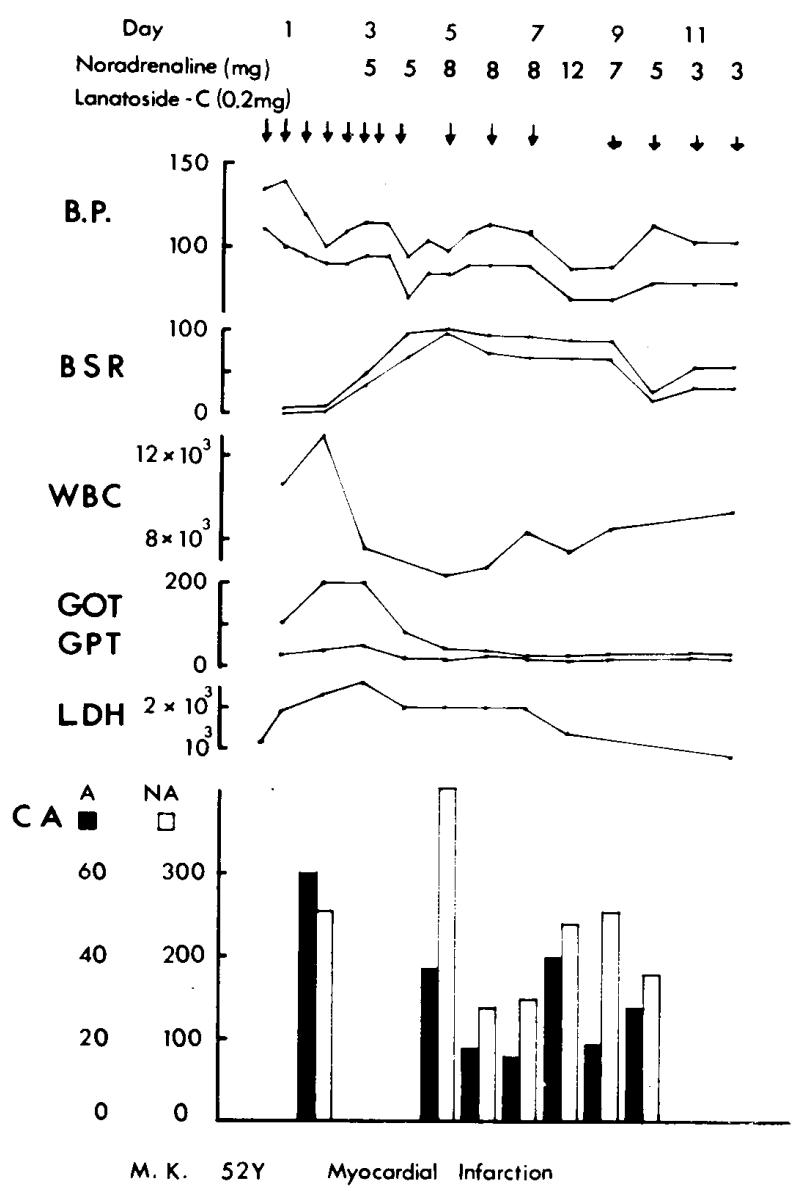

Fig.4. Clinical course and changes in urinary excretion of catecholamine of Case 3 with extensive anterior myocardial infarction.

Fig. 8 shows changes of the myocardial CA content of rabbits following coronary ligation. The ligated group showed decrease of CA content both in the infarcted and non-infarcted area six hours after the ligation, as compared with the control group. The content in the non-infarcted area was slightly lower than that in the infarcted area. Three days after the ligation, the noninfarcted area showed further decrease in CA content than the infarcted area, with a significant difference between these two areas. The CA in the non-infarcted area tended to increase seven days after the ligation, while the $\mathrm{CA}$ in the infarcted area continued to further decrease. 14 days after the ligation, the CA content in the non-infarcted area was recovered to virtually a comparable level to that in the control, but the content in the infarcted area was further decreased.

When these animals were given exogenous NA (Fig. 9), the NA uptake in the infarcted area was not so markedly decreased three days after the ligation, as compared with that in the control, whereas it was markedly decreased 14 days after the ligation. In the non-infarcted area, on the other hand, the degree of NA uptake showed the significant decrease in three days after the ligation, but was restored to normal level in 14 days.

Shown in Fig. 10 are the findings of other organs. The CA content in the adrenal glands was markedly decreased six hours after the ligation, and failed to restore normal even 14 days later. The CA content in the spleen was slightly decreased seven days after the ligation, but 14 days later showed higher content than that in the control group. The CA content in the lungs and in the kidneys showed no" significant change.

Changes in the urinary excretion of CA of the rabbits after coronary ligation are shown in Fig. 11. The animals showed marked increase in urinary excretions of both A and NA immediately after the ligation, as compared with the control animals. The increased excretion of NA remained longer than that of $\mathrm{A}$.

Rabbits were injected with $1 \mathrm{mg}$ of betamethasone per $\mathrm{kg}$ of body weight, or $0.1 \mathrm{mg}$ of reserpine per $\mathrm{kg}$ immediately after the ligation of coronary artery, and asșayed for myocardial CA content in the infarcted area and non-infarcted area six hours later (Table II). The administra- 

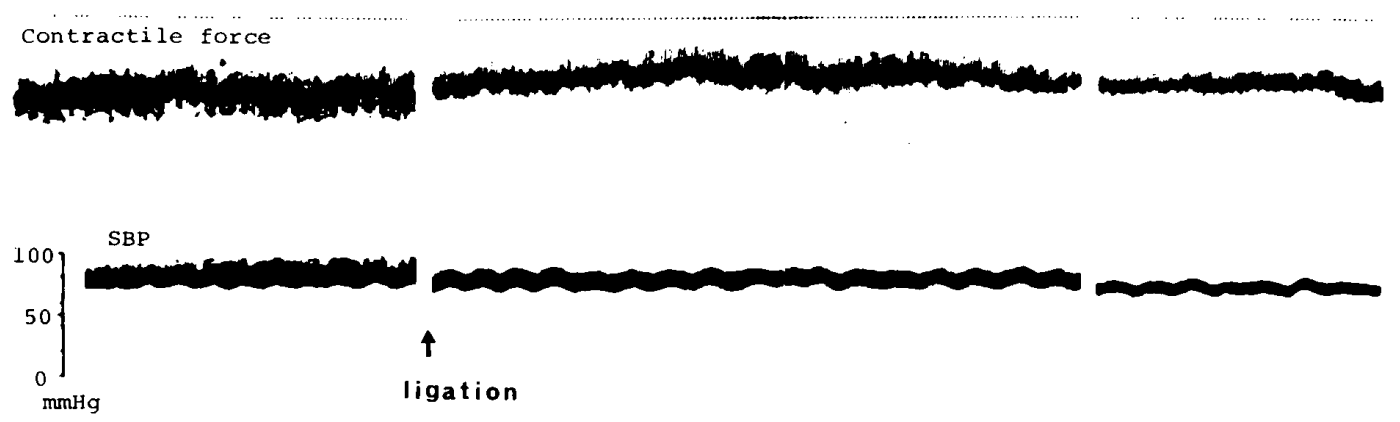

Fig.5. Changes of contractile force in myocardium and systemic blood pressure following the ligation of descending branch of left coronary artery in rabbits.

Contractile force
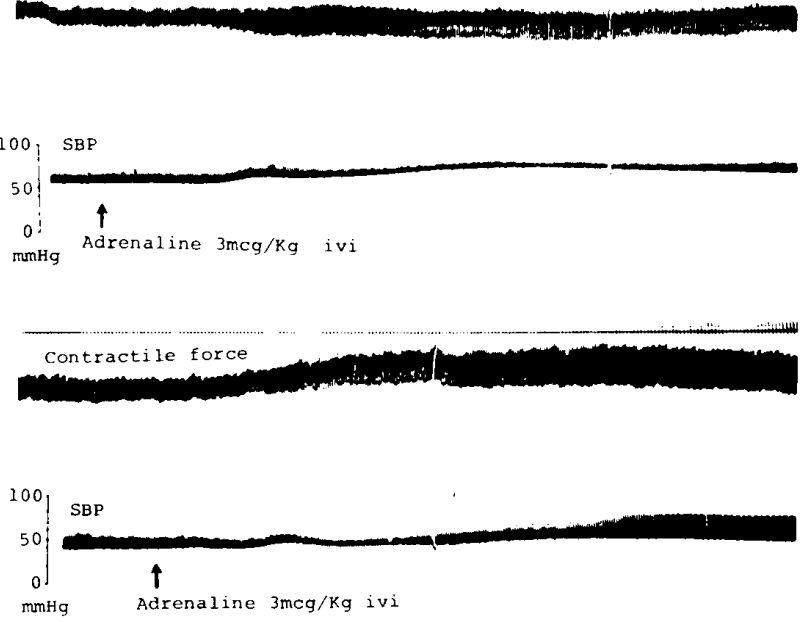

Contractile force

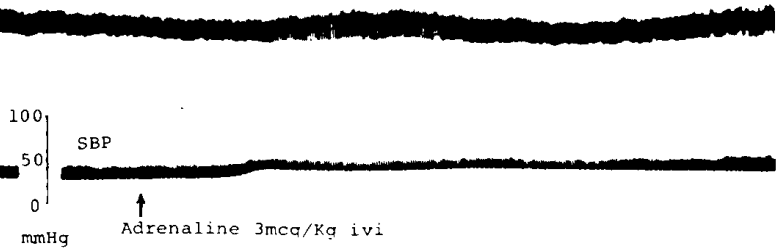

Fig.6. Myocardial contractile force of the left ventricle and blood pressure after the intravenous administration of adrenaline $(3 \mathrm{mcg} / \mathrm{kg})$ to the rabbit with intact coronary artery (upper column), with incomplete (middle) and with complete obstruction (lower) of the left descending artery.

tion of reserpine markedly decreased the myocardial CA content in both infarcted and noninfarcted area. The medication with betamethasone caused less decrease of the CA content in the infarcted and non-infarcted area than that in unmedicated animals.
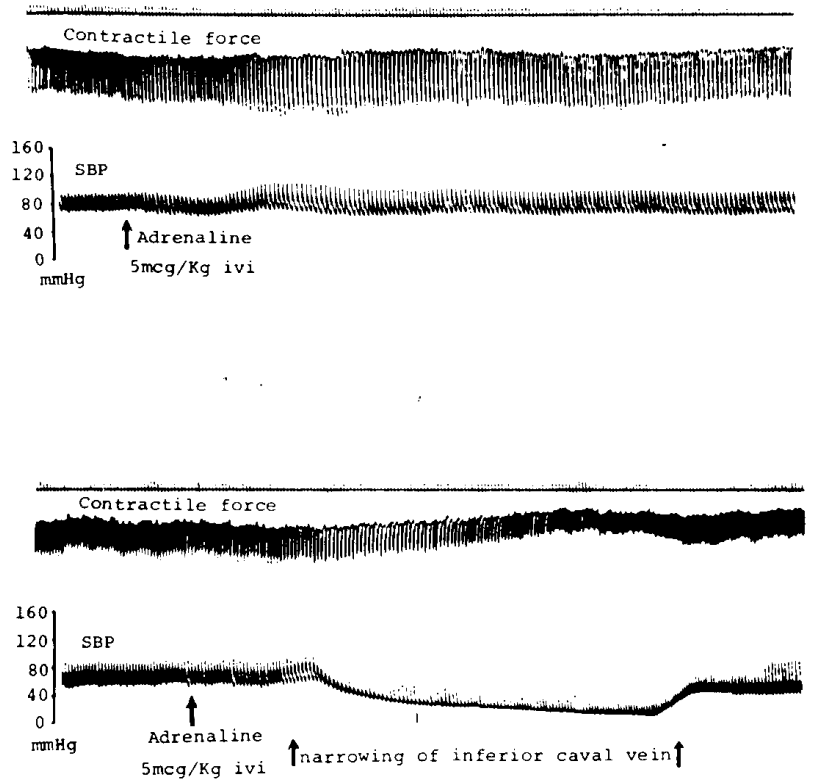

Fig.7. Effects of adrenaline on contractile force in myocardium and systemic blood pressure following the narrowing of inferior caval vein in rabbits.

\section{Discussion}

It has been known that the CA level in the plasma and urine are markedly increased in myocardial infarction. ${ }^{-4}$ Since it is accepted that the $\mathrm{CA}$ in the plasma and urine reflects the state of sympathetic activity in the living organism, it may be supposed that the sympathetic activity is markedly enhanced in the acute stage of myocardial infarction. There are various opinions about the pathophysiological mechanism through which the sympathetic activity is enhanced. There is such opinion that, as mental or physical stress can induce anginal attack, so can the sympathetic hyperactivity be the cause of myocardial infarction.11 There are also speculations 
TABLE II CATECHOLAMINE CONTENT $(\mathrm{mcg} / \mathrm{g})$ IN THE HEART MUSCLE SIX HOURS AFTER THE LIGATION OF CORONARY ARTERY IN RABBITS

\begin{tabular}{lccc}
\hline \hline & $\begin{array}{c}\text { No. of } \\
\text { cases }\end{array}$ & $\begin{array}{c}\text { infarcted } \\
\text { area }\end{array}$ & $\begin{array}{c}\text { non-infarcted } \\
\text { area }\end{array}$ \\
\hline Group with sham operation & 5 & & $1.83 \pm 0.07$ \\
Group with coronary ligation Control & 5 & $1.36 \pm 0.12$ & $1.07 \pm 0.07$ \\
Betamethasone $(1 \mathrm{mg} / \mathrm{kg})$ & 5 & $1.59 \pm 0.13$ & $1.46 \pm 0.21$ \\
Reserpine $(0.1 \mathrm{mg} / \mathrm{kg})$ & 3 & $0.26 \pm 0.05$ & $0.34 \pm 0.03$ \\
\hline
\end{tabular}

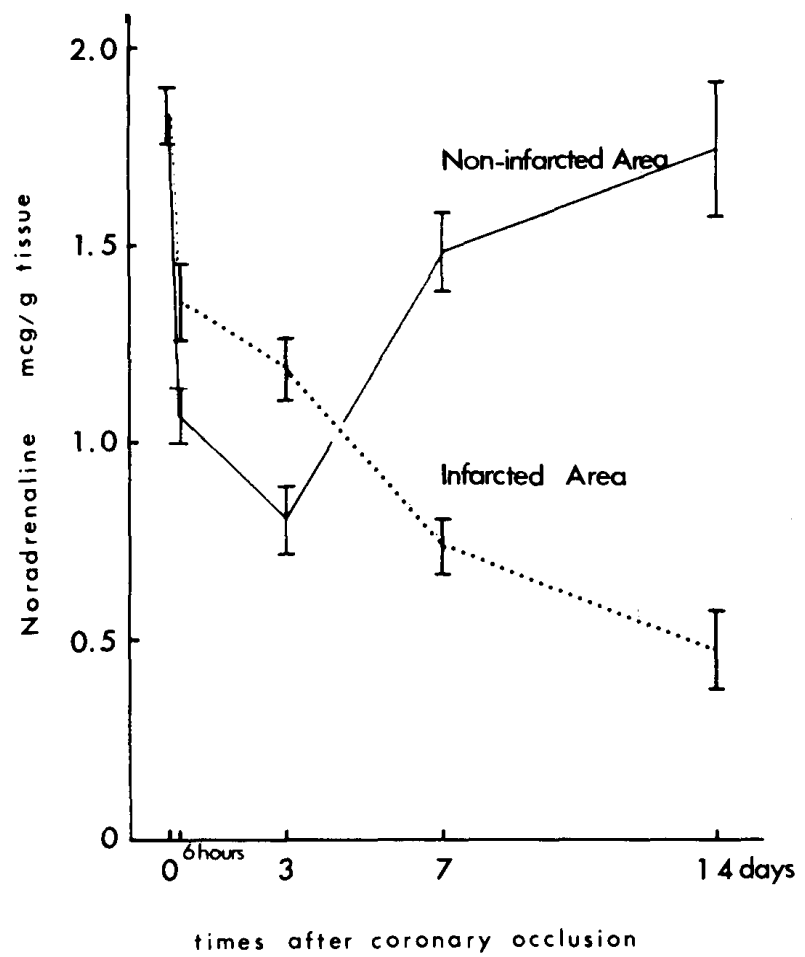

Fig.8. Changes in tissue content of noradrenaline following the ligation of coronary artery. Vertical lines represent the standard error of the mean.

that the increased $\mathrm{CA}$ in the urine and plasma results from biological reaction to pain, shock or heart failure, ${ }^{12,13}$ as well as the release of CA from the infarcted area in the myocardium. ${ }^{14}$

It is said that when humans or animals are treated with an exogenous CA, 2 to $5 \%$ of its dose is excreted into urine without undergoing metabolism. ${ }^{15}$ As observed in Case 3 , the increased CA in the urine at the early stage was comparable to that in later stage when a high dose of CA was administrated, and it is supposed that a large amount of CA is released at the early stage of myocardial infarction. Since the finding that the CA content in the non-infarcted area was more markedly decreased than that in the infarcted area in the myocardium specimens from autopsied patients with recent myocardial infarction or from rabbits in early stage of experimental myocardial infarction, it is obvious that such a large amount of CA cannot be attributed to the release from the degenerated tissue of infarcted myocardium.

Because no relation was observed between the urinary excretion of $\mathrm{CA}$ and the clinical symptoms like chest pain, leucocyte count and S-GOT, as was observed in Case 1 and 2 , it is unreasonable to consider that the increased urinary excretion of CA results from the biophylaxis to pain or dolorogenic substance. Wallace et al. ${ }^{16}$ stated that "the CA excretion was substantially higher in patients with acute myocardial infarction than it was in patients admitted to a coronary care unit with chest pain subsequently proven not to have been a consequence of myocardial infarction".

In early study, Raab et al. ${ }^{17}$ reported that the CA content was increased in the myocardium of autopsied patients with myocardial infarction, whereas Bloodwooth ${ }^{18}$ described that it was decreased. Recent reports of experimental myocardial infarction generally indicate a decrease in the CA content in the infarcted myocardium.19,20 In a paper on experimental canine myocardial infarction, Mathes et al. ${ }^{20}$ showed that the CA content in the infarcted area become totally absent four days after the ligation of the coronary artery, while in the non-infarcted area of the myocardium of the left ventricle the $\mathrm{CA}$ content tended to decrease during the first ten days after the infarction, then gradually increased, and returned to the normal level in six weeks. This finding by Mathes et al. confirms the author's findings.

In the present study, the myocardial CA con- 


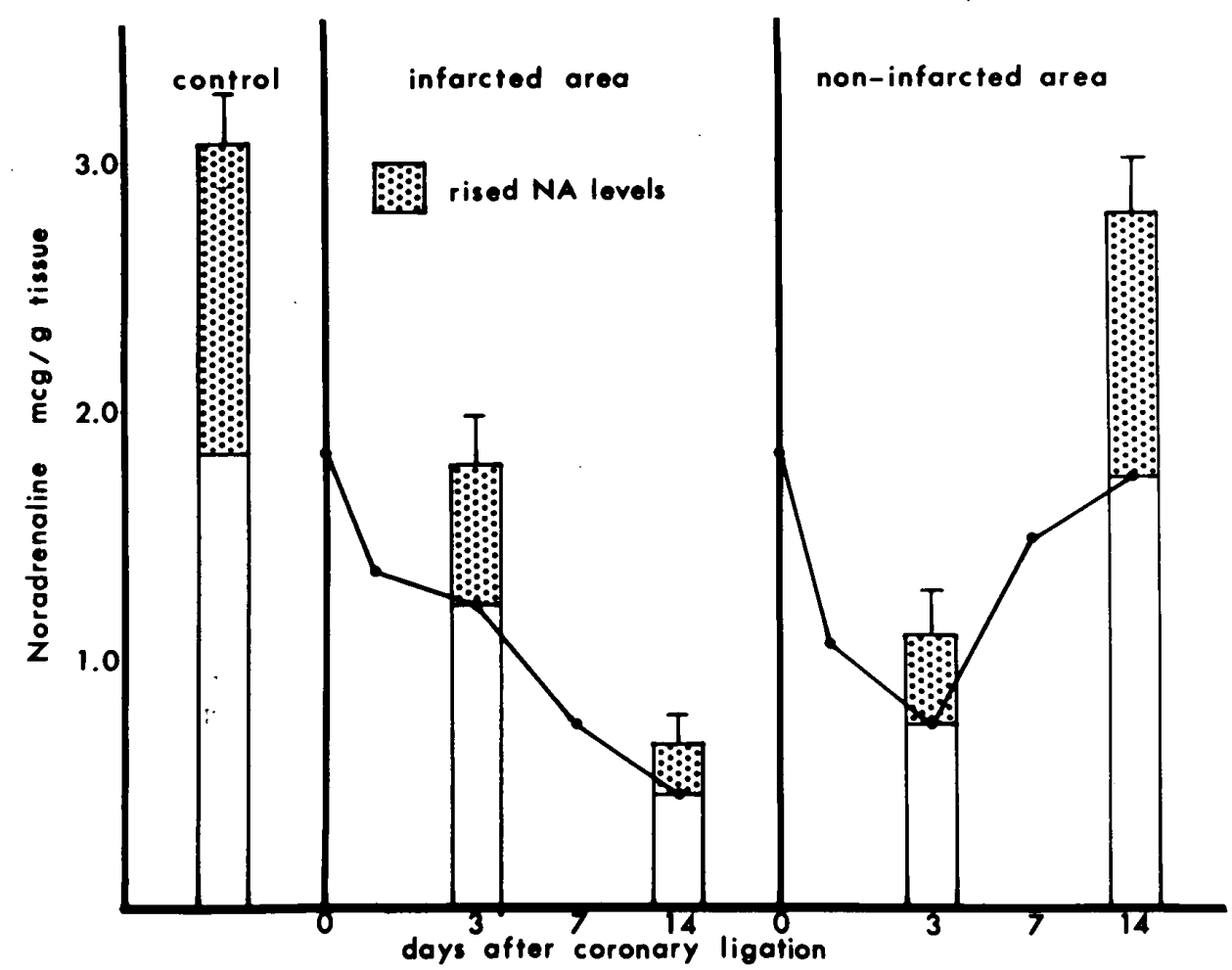

Fig.9. Changes in tissue content of noradrenaline in infarcted and non-infarcted heart muscle after noradrenaline infusion $(100 \mathrm{mcg} / 20 \mathrm{ml} / 30 \mathrm{~min})$. Vertical lines represent the standard error of the mean.

tent in the non-infarcted area showed more decrease than that in the infarcted area six hours and three days after the ligation (Fig. 8). This predominant decrease in CA content in the noninfarcted area was also observed in the myocardial specimens from the autopsied patients who died in the acute stage of myocardial infarction (Table I). The predominance in decrease of CA content in the non-infarcted area observed in early stage of this experiment disappeared in the stage more than seven days after the ligation (Fig. 8). Then the CA content in the non-infarcted area tended to be recovered and restored virtually to the same level as that in the control animals two weeks after the ligation, whereas the content in the infarcted area continued to decrease upto two weeks after the ligation.

The CA content in the adrenal glands showed following changes (Fig. 10): the content rapidly decreased soon after the ligation, and remained low even 14 days after the ligation. This finding suggests that sympathetic hyperactivity remains even 14 days after the production of infarction, and also that the adrenal glands supply with CA to other organs via blood stream. The speculation that the adrenal glands supply CA to other organs is supported by the observation of changes in $\mathrm{CA}$ content in the spleen, which is considered as a storing organ of CA. The CA content in the spleen was low seven days after the ligation, but it was rather higher than the control 14 days after the ligation.

The rabbits with experimental myocardial infarction showed the significant decrease in the NA uptake rate into the myocardium of noninfarcted area in the acute stage. This finding indicates that the non-infarcted area of the myocardium is capable of uptaking and storing the circulating NA, and, at the same time, indicates that the amount of NA released from the myocardium by sympathetic hyperactivity exceeds the stored amount of NA. These findings of change in CA metabolism in myocardial infarction are similar to the reports on the behavior of the CA in congestive heart failure. In other words, the urinary excretion of CA is markedly increased in congestive heart failure, $8,10,21-24$ and there are also studies on CA in animals with experimental heart failure, indicating the increased urinary excretion of $\mathrm{CA}$ and the decreased $\mathrm{CA}$ in the myocardium, 8,22 and also the decreased myocardial NA uptake. ${ }^{8}$ In a paper 


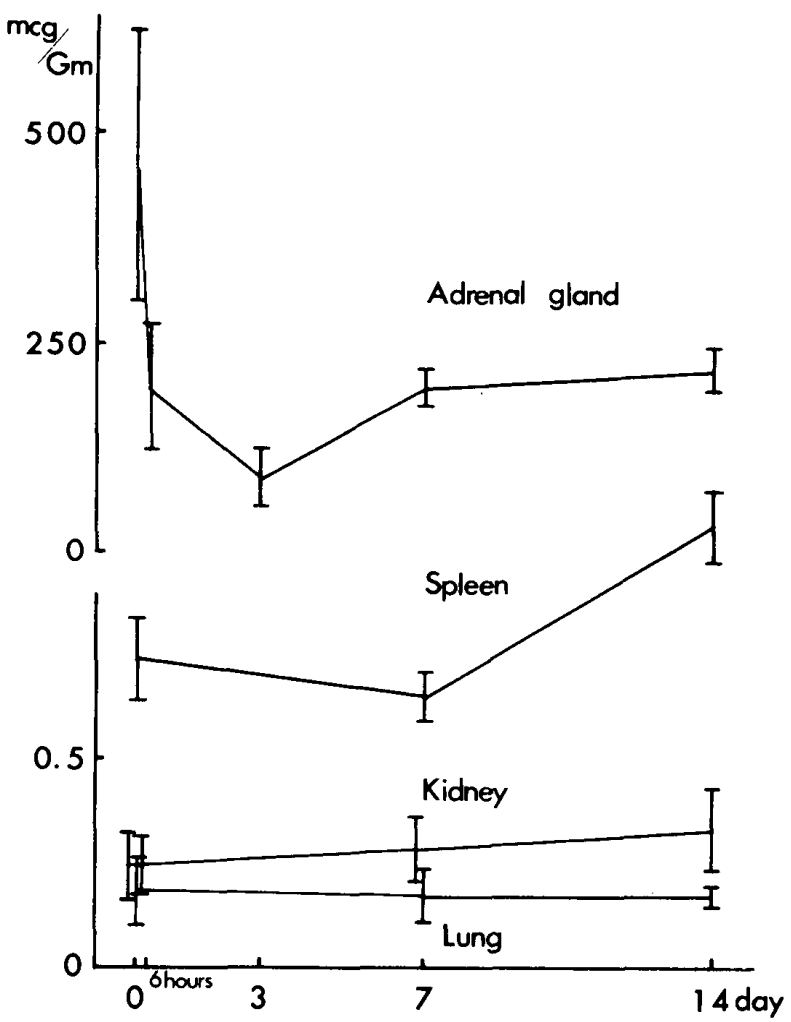

Fig.10. Changes of catecholamine contents in various organs in rabbits following the coronary ligation. Vertical lines represent the standard error of the mean.

on the comparative study of the effect of digitalis and changes in the urinary excretion of CA in patients with heart failure, 21 it is described that the increased CA, namely, the sympathetic hyperactivity, plays an important role in improving heart failure, and administration of sympatholytic drug such as reserpine exacerbates the symptoms of heart failure. From these published evidences, it is surmised that the activity of the sympathoadrenomedullary system is enhanced in congestive heart failure, and that the sympathetic hyperactivity is a reasonable biophylactic reaction for improvement of cardiac function. As mentioned above, there are many common features in CA metabolism between congestive heart failure and myocardial infarction, and it may be supposed that, in the early stage of myocardium of the non-infarcted area undergoes the similar alteration in CA metabolism which is seen in the myocardium of failing heart. That is, in other words, in order to counteract the cardiac hypofunction induced by myocardial infarction, the sympathetic activity is enhanced, and activates the function of the non-infarcted area of the myocardium, and subsequently contributes to improving cardiac function. The gradual decrease in urinary excretion of $\mathrm{CA}$ and the gradual increase in CA content in the noninfarcted area of the myocardium in the later stage of myocardial infarction may imply the gradual recovery from heart failure and gradual reduction in the sympathetic hyperactivity.

In the present experiments, it was observed that the CA content in the infarcted area of the myocardium decreased gradually over the acute stage to the chronic stage, and that the NA uptake was relatively high three days after the ligation when the elevated S-T segments were seen on the electrocardiogram, but was markedly low in the chronic stage of 14 days after the ligation when the depressed $T$ waves were seen on Ecg. These findings indicate that the sympathetic nerve endings in the infarcted area is still capable of uptaking and storing NA, and also suggest that the activities of CA metabolizing enzymes such as monoamine oxidase and catechol-omethyl transferase may be suppressed in the infarcted area in the acute stage of myocardial infarction. And also it may be considered that in the stage more than three days after the ligation when the elevated S-T segments disappear from the Ecg, not only the myocardium but the sympathetic nerves are fibrosed, and its NA uptaking and storing capacity is gradually lost. The infarcted area showed a high NA uptake in the early stage of infarction, it will be reasonable to suppose that the uptake is performed through the collateral circulation to the infarcted area or directly through the intracellular fluid from the ventricular cavity.

As mentioned above, the author showed that the sympathetic activity was enhanced in the acute stage of myocardial infarction, and that this sympathetic hyperactivity contributed to improvement of hemodynamics. While it has been pointed out that $\mathrm{CA}$ also possesses exacerbative factors, such as increasing cardiac oxygen consumption with diminution of cardiac efficiency, and producing myocardial hypoxia with lactic acid accumulation, and further, an excessive dose gives rise to necrosis of the myocardium.11 For these reasons, it has, in recent years, been discussed whether it is adequate or not to administer pressor amines for treatment of shock due to myocardial infarction. It has been stated by Corday 5 that the pressor amines increase the coronary blood flow and decrease the coronary vascular resistance through restor- 


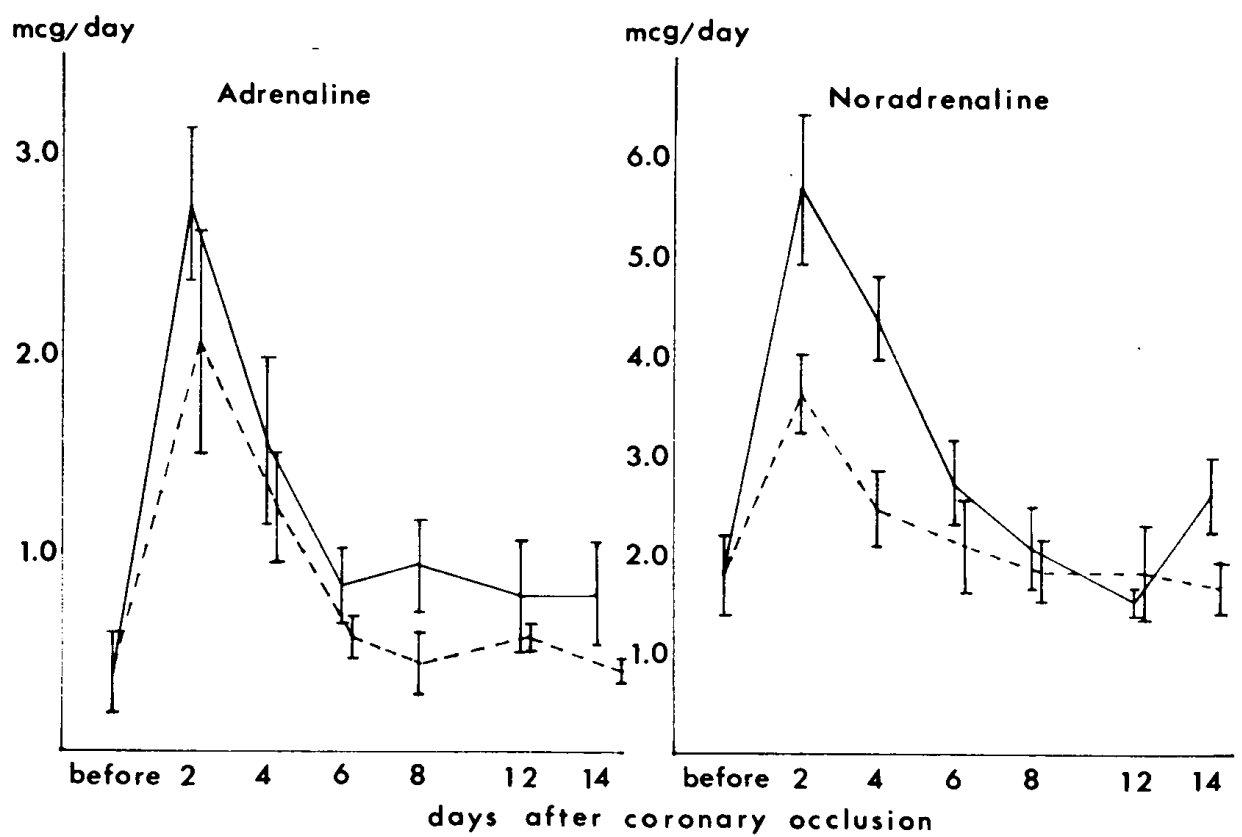

Fig.11. Changes of urinary excretion of catecholamine following experimental myocardial infarction.

- : coronary occlusion

.... : control

ing the blood pressure, and that careful application of pressor amines is substantial for improving and maintaining cardiac function. It has further been shown by Sarnoff," that "inotropic and oxygen consumption effects of NA could be dissociated over dosage range which produce substantial increase in myocardial contractility", and adequate dosage of "NA causes marked increase in myocardial contractility as well as pronounced fall of left ventricular end-diastolic pressure without increasing myocardial oxygen consumption". In the present experiments, it was observed that the ligation of the coronary artery resulted in decrease of myocardial contractility, accompanied by the fall in the blood pressure and pulse pressure; and when CA was administrated intravenously, the myocardial contractility, blood pressure and pulse pressure were increased (Fig. 6). This effect of CA was markedly suppressed by compression of the inferior caval vein (Fig. 7), and it may, therefore, be supposed that this effect of CA is supported by the maintenance of venous return. It has also been reported that the venous return is markedly increased by intravenous injection of $\mathrm{CA}^{26}$ it is considered that this cardiac effect of CA may partly owes to the increment in venous return.
The author has discussed from various points of view that the sympathetic hyperactivity contributes to improving the cardiac function in the presence of heart failure of various causes. In order to understand the pathophysiological role of CA still further, the author observed the effect of adrenocorticosteroids on the sympathetic activity, since the drug is used for prevention of arrhythmia and treatment of cardiogenic shock. Betamethasone showed the suppressed decrease in CA content in the myocardium in rabbits (Table II). It is not clear, however, whether this finding can be interpreted as indicating that the sympathetic hyperactivity was reduced by the corticosteroid or the direct effect of corticosteroid on CA metabolism. There is a paper reporting that the cortisol level in the plasma is increased in the acute stage of myocardial infarction. 27 For this reason, it is supposed that there exists a mechanism to activate cardiac function controlled by both $\mathrm{CA}$ and adrenocorticosteroids. Elucidation of this mechanism may be considered of significance in clinical application of corticosteroids for treating myocardial infarction.

\section{SUMMARY}

In an attempt to elucidate the pathophy- 
siological significance of the sympathetic hyperactivity in the acute stage of myocardial infarction, the author observed changes in the urinary excretion of $\mathrm{CA}$, the $\mathrm{CA}$ content in the myocardium and the hemodynamics in both clinical and experimental myocardial infarction, and the following were found:

1) In clinical myocardial infarction, the urinary excretion of CA was markedly increased immediately after an attack, and the assay of myocardial specimens form the autopsied patients of acute myocardial infarction revealed that the CA content in the non-infarcted area was lower than that in the infarcted area.

2) In the experiments on rabbits with ligated coronary artery, the increase in cardiac contractility and rise in blood pressure in response to $\mathrm{CA}$ was suppressed after the ligation of coronary artery. In the early stage of experimental myocardial infarction, the decrease of myocardial CA content in the non-infarcted area was, as in autopsied patients, predominant over the decrease of that in the infarcted area. In the chronic stage (more than one week after the coronary ligation), the CA content in the infarcted area showed further decrease, but in the non-infarcted area it was recovered to the level in the control animals. The uptake of exogenous NA into the non-infarcted area decreased in the acute stage, and in the infarcted area it showed marked decreased in the chronic stage. The urinary excretion of CA was increased in the acute stage of myocardial infarction.

3) The administration of betamethasone suppressed the decrease in the CA content in the myocardium following the ligation of coronary artery.

Based on these findings, the author came to a postulation that the sympathetic hyperactivity which is suggested by increased urinary excretion of CA and decreased CA content in the myocardium results from the reasonable biophylactic reaction so as to supplement the cardiac hypofunction derived from myocardial infarction.

\section{Acknowledgement}

The author expresses his sincere gratitude to Professor T. Tomomatsu and Dr. Y. Ueba for their kind guidance, and also to his co-workers for their enthusiastic cooperation.

\section{REFERENCES}

1. GAZES, P. C., RICHARDSON, J. A., \& WOOD,
E. F.: Plasma catecholamine concentration in myocardial infarction and angina pectoris. Circula. tion 19: 657, 1959.

2. McDONALD, L., BARKER, C., McDONALD, A., \& RESTIEAUX, N.: Plasma catecholamine after cardiac infarction. Lancet 2: 1021, 1969.

3. NUZUM, F. R. \& BISCHOFF, F.: The urinary output of catechol derivatives including adrenaline in normal individual, in essential hypertension, and in myocardial infarction. Circulation 7: 96, 1953.

4. KLEIN, R. F., TROYER, W. G., THOMPSON, H. K., BOGDONOFF, M. D., \& WALLACE, A. G.: Catecholamine excretion in myocardial infarction. Arch. Intern. Med. 122: 476, 1968.

5. CORDAY, E. \& LILEHEI, R. C.: Pressor agents in cardiogenic shock. Am. J. Cardiol. 23: 900, 1969.

6. RAAB, W., VAN LITH, P., LEPESCHKIN, E., \& HERRLICH, H. C.: Catecholamine-induced myocardial hypoxia in the presense of impaired coronary dilatability independent of external cardiac work. Am. J. Cardiol. 9: 455, 1962.

7. VON EULAR, U. S., \& FLORDING, I.: A fluorometric micromethod for differential estimation of adrenaline and noradrenaline. Acta Physiol. Scand. 33 (supple. 118): 45, 1955.

8. ITO, Y.: The tissue catecholamine concentration in experimental cardiac failure. Jap. Circul. J. 32: $761,1968$.

9. CROUT, J. R., CREVELING, C. R., \& ROSENGREN, E.: A method for the fluorometric determination of adrenaline and noradrenaline in tissue. Acta Physiol. Scand. 44: 273, 1958.

10. TOMOMATSU, T. \& UEBA, Y.: Cardiac failure and catecholamine. Jap. Circul. J. 30: 49, 1966.

11. RAAB, W.: Emotional and sensory stress factors in myocardial pathology. Am. Heart J. 72: 538, 1966.

12. VAROLI, C., THOMAS, M., \& SHILLINGFORD, J.: Free noradrenaline and adrenaline excretion in relation to clinical syndromes following myocardial infarction. Am. J. Cardiol. 20: 605, 1967.

13. SIGGER, D. C., SALTER, C., \& FLUCK, D. C.: Serial plasma adrenaline and noradrenaline levels in myocardial infarction using an new double isotope technique. Brit. Heart J. 33: 878, 1971.

14. RUSSEL, R. A., CRAFOORD, J., \& HARRIS, A. S.: Changes in myocardial composition after coronary artery ligation. Am. J. Physiol. 200: 995, 1961.

15. KONDO, Y.: Studies on catecholamine in relation to the autonomic nervous system and urinary excretion. Fol. Endocr. Jap. 43: 497, 1967.

16. WALLACE, A. G. \& KLEIN, R. F.: Role of catecholamine in acute my ocardial infarction. $A m$. J. Med. Sci. 258: 139, 1969.

17. RAAB, W. \& GIGEE, W.: Norepinephrine and epinephrine content of normal and diseased human heart. Circulation 11: 593, 1955.

18. BLOODWOOTH, B. M. \& VON HAAM, E.: The tissue catecholamine concentration of the human heart determined by the aluminum hydroxide-arsenom olybic acid method. Circulation 13: 573, 1956.

19. RICHARDSON, J. A., WOODS, E. F., \& BAGWELL, E. E.: Circulating epinephrine and norepinephrine 
in coronary occlusion. Am. J. Cardiol. 5: 613, 1960.

20. MATHES, P. \& GUDBJARNASON, S.: Change in norepinephrine store in the canine heart following experimental myocardial infarction. Am. Heart $J$. 81: $211,1971$.

21. MATSUMOTO, T.: The studies on catecholamine; with special reference to cardiac failure. Jap. Circul. J. 31: 481, 1967.

22. CHIDSEY, C. A., BRAUNWALD, E., \& MORROW, A. G.: Catecholamine excretion and cardiac store of norepinephrine in congestive heart failure. $\mathrm{Am}$. J. Med. 39: 442, 1965.

23. TOMOMATSU, T., UEBA, Y., et al.: Catecholamine in congestive heart failure (Report I). Jap. Heart J. 4: 13, 1963. (in Japanese)

24. TOMOMATSU, T., UEBA, Y., et al.: Catecholamine in congestive heart failure (Report II). Jap.
Heart J. 8: 242, 1967. (in Japanese)

25. SARNOFF, S. J., GILMORE, J. P., WEISFELDT, M. L., DAGGET, W. M., \& MANSFIELD, P. B.: Influence of norepinephrine on myocardial oxygen consumption under controlled hemodynamic condition. Am. J. Cardiol. 16: 217, 1965.

26. TOMOMATSU, T., INOH, T., MATSUMOTO, E., KOTERAZAWA, M., MAEDA, T., \& YOSHITAKE, $K$ : : Significance of venous return of development of pulmonary edema. Jap. Circul. J. 29: 353, 1965.

27. CEREMUZYNSKI, L., KUCH, J., MARKIEWICZ, L., LAWECKI, J., \& TATON, Y.: Pattern of endocrine reactivity in patients with recent myocardial infarction; clinical and biochemical correlations; trial of endocrine therapy. Brit. Heart J. 32: 603, 1970. 